\title{
INVESTIGATION OF THE GROWTH AND STRUCTURE OF THE TIBIA OF THE RABBIT BY MIGRORADIOGRAPHIC AND AUTORADIOGRAPHIC TECHNIQUES
}

\author{
Matreen OWen,* Jenifer Jowsey and Janet Valghan, Oxford, Exglaid \\ Nuffield Department of Medicine and Nuffield Institute for Medical Research, Oxford
}

Previous investigations on the structure and growth of long bones have been made by many and varied techniques. As early as 1727 Hales first demonstrated experimentally by drilling holes to act as markers that in the growing bone the markers always remained at the same distance apart and that there was therefore no interstitial growth. This has been subsequently confirmed by many workers using the technique of markers of madder feeding (Duhamel 1742, Hunter in about 1772, Payton 1931-32, Brash 1934, Bisgard and Bisgard 1935) and of the radiographic study of the lines of arrested growth (Harris 1933). It was also noted that growth in width was different along the length of the bone (Duhamel 1743). Lacroix (1951) studied transverse growth in detail by routine histological techniques. It is now accepted that, in general, transverse growth depends on the formation of new bone on the endosteal surface of the metaphysial funnel and on the periosteal surface of the cylindrical shaft, together with simultaneous removal of bone from the periosteal and endosteal surfaces respectively at the same sites.

Studies with radioactive isotopes have confirmed these findings and added many new details. Radioactive phosphorus has been used as a tracer to demonstrate the growth of the tibia-fibula in rats (Leblond et al. 1950). A single intravenous injection of the radioactive isotope was given and the animals sacrificed at various times after injection. In confirmation of previous ideas these authors have shown how endosteal deposition on the metaphysis associated with periosteal resorption as part of the remodelling process of the funnel accounts for increase in length of the cylindrical shaft of the bone as the animal grows older without " interstitial growth of bone." ${ }^{45} \mathrm{Ca}$ has also been used in rats (Tomlin, Henry and Kon 1953). In these experiments rats thirty days old received a daily diet containing radioactive calcium. The growth of the femur and humerus was then studied by observing the position of the nonradioactive bone with respect to the radioactive bone at various time intervals after starting the diet. The results show how differences in deposition of new bone on the anterior and posterior walls are related to the curvatures of the bone cortex. Observations on the uptake of radioactive strontium in rabbits (Kidman et al. 1952, Jowsey et al. 1953a, Jowsey, Owen and Vaughan 1953b) and in pigs (Comar, Lotz and Boyd 1952) have shown that the sites of deposition of this isotope in the bones correspond with those of the formation of new bone tissue, and many new facts concerning its rate of uptake and position in animals of different ages have been recorded.

Previous work with the autoradiographic technique has been done using longitudinal sections of bone. There are, however, inherent limitations to the information which can be obtained in this way. In the present investigation, which is a study of the growth of the proximal half of the tibia of the rabbit, it was therefore decided to use transverse sections, making use of both microradiographic and microautoradiographic techniques. Microradiographs of transverse sections reveal structural features not evident under the ordinary microscope-in particular, variation in degrees of calcification in different areas of bone. For the preparation of the autoradiographs, ${ }^{90} \mathrm{Sr}$, which emits $\beta$ particles of maximum energy $0.53 \mathrm{mev}$ and has a half-life of twenty-five years, was used as a tracer. The animals were injected with a single dose of carrier-free ${ }^{90} \mathrm{SrCl}_{2}$ solution and killed at various times after injection. A study of the position of the isotope incorporated at the time of injection was then made.

* Nuffield Graduate Assistant. 


\section{EXPERIMENTS}

Rabbits came from the same stock as before (Kidman et al. 1952). They were injected with a single dose of carrier-free ${ }^{90} \mathrm{SrCl}_{2}$ (about $800 \mu \mathrm{c}$ per kilogram body weight). Table I gives details of the rabbits studied.

TABLE I

Details of RabBits USED in the Experiments

\begin{tabular}{|ccc|}
\hline $\begin{array}{c}\text { Age when } \\
\text { injected }\end{array}$ & $\begin{array}{c}\text { Time after injection } \\
\text { when killed }\end{array}$ & $\begin{array}{c}\text { Number } \\
\text { of rabbits }\end{array}$ \\
\hline $5-7$ weeks & $1-3$ days & 3 \\
$5-7$ weeks & 8 weeks & 2 \\
$5-7$ weeks & 6 months & 2 \\
6 months & 1 day & 1 \\
6 months & 17 days & 1 \\
6 months & 6 months & 1 \\
10 months & 1 day & 1 \\
\hline
\end{tabular}

A study of the uptake of ${ }^{90} \mathrm{Sr}$ was made in young and actively growing animals, five to seven weeks old (weanling), and in older animals of six months and older. Both microradiographs and autoradiographs were obtained of a series of transverse sections of the proximal half of the tibia-fibula, extending from just below the epiphysial plate to the middle of the shaft.

Microradiographs of corresponding sections from the tibia of rabbits which had received no isotope were also obtained for comparison. A list of these is given in Table II.

TABLE II

Details of Rabbits Used as Controls

\begin{tabular}{|rc|}
\hline Age of rabbit & Number of rabbits \\
\hline 57 weeks & 3 \\
31 months & 2 \\
7 months & 3 \\
12 months & 1 \\
\hline
\end{tabular}

Techniques - The technique of cutting and grinding undecalcified sections of bone to a thickness of about $50 \mu$ and of preparing both microradiographs and autoradiographs has already been described (Kidman et al. 1952, Jowsey, Owen and Vaughan 1953b). The sections which were cut and examined in series were numbered 1 to $n$, number 1 being at the middle of the shaft. Adjacent sections were about $0 \cdot 5$ millimetres apart.

\section{RESULTS}

MICRORADIOGRAPHS

A detailed account of the microradiographs of the non-radioactive rabbits is given which ensures that the characteristics to be described are in no way due to any effects from radioactive strontium. The general features of growth are most easily distinguishable in the rabbits five to seven weeks old and three and a half months old. There is slower growth in length after three and a half months, and the bone of the seven-month and twelve-month old rabbits is merely thicker

vol. $37 \mathrm{~B}$, No. 2 , MAY 1955 
and more mature. Figure 1 is a diagrammatic model of the tibia-fibulae of rabbits of five to seven weeks, three and a half months, and seven months old. The numbers at the side correspond to the level from which particular cross-sections are taken.

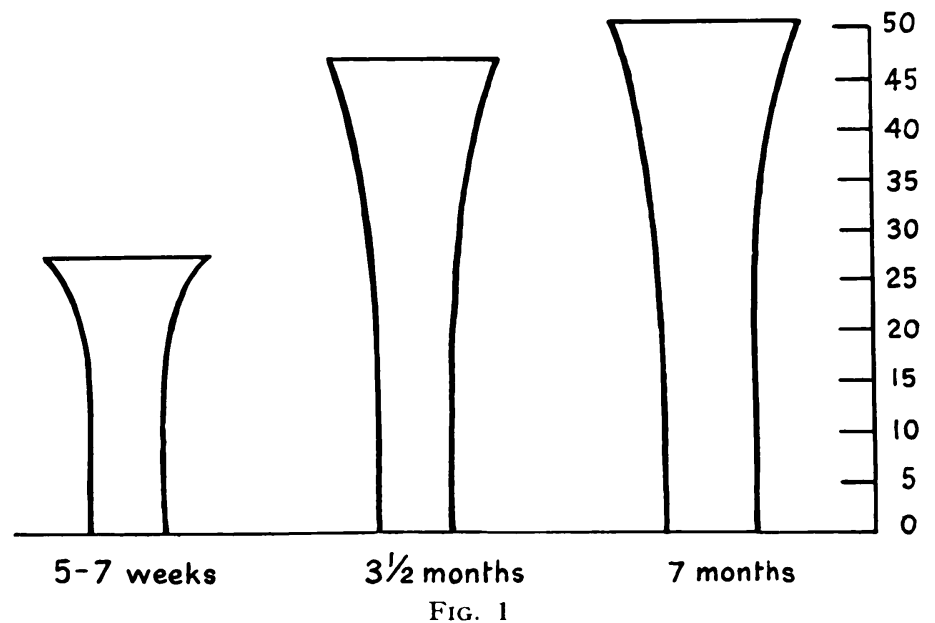

Diagrammatic representation of the relative sizes of the proximal half of the tibiae-fibulae of rabbits aged five to seven weeks, three and a half months and seven months. Numbers at the side correspond to the positions of sections referred to in the text.

One of the most striking observations is the large number of remnants of highly calcified cartilage found throughout the length of the bone studied in animals of all ages. These cartilage remnants and the bone in which they are embedded are presumably the remains of

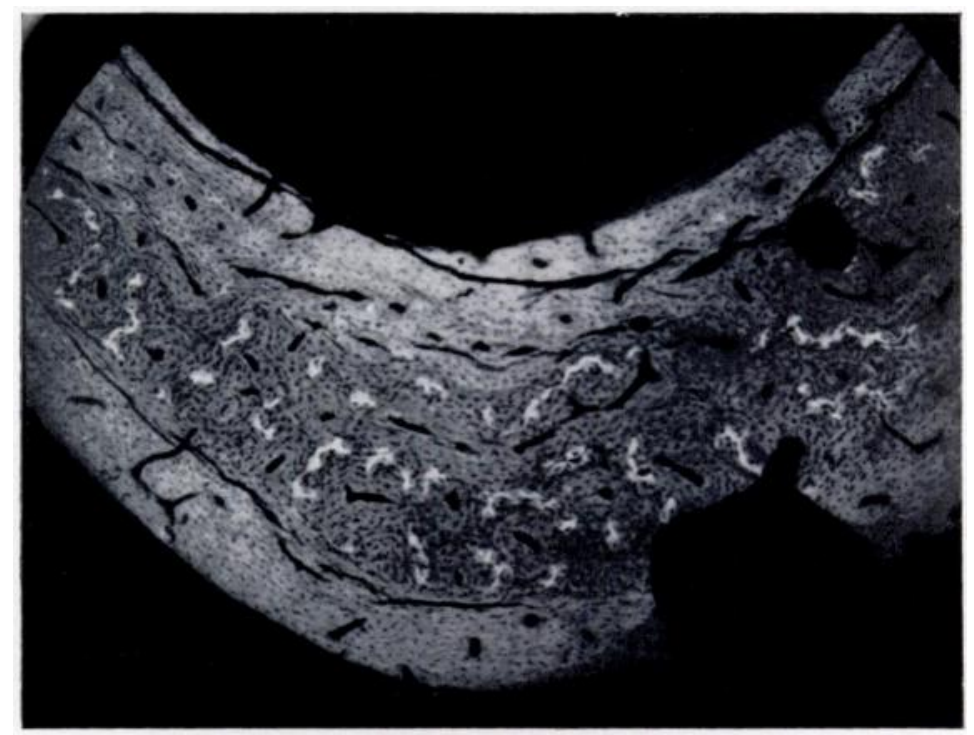

Fig. 2

Microradiograph showing highly calcified cartilage remnants in band of epiphysial bone. Part of section 15 from the tibia of a rabbit aged three and a half months. $(\times 30$.

the epiphysial bone formed when the epiphysial plate was at this level (Jowsey, Owen and Vaughan 1955). Figure 2 , taken from section 15 of the three and a half months old rabbit, shows part of the band of epiphysial bone remaining at this level. The highly calcified cartilage shows 
up as white zig-zag lines; more recently formed non-Haversian bone can be seen on the periosteal and endosteal surfaces.

In sections taken in order from the mid-shaft towards the epiphysis the distribution of remnants of highly calcified cartilage presents a definite picture which varies little from one animal to another of the same age and only in degree amongst animals of different ages. A study of the distribution of these remnants in the sections shows how and where new bone has been formed during growth.

Serial cross-sections of the tibia of the rabbit aged five to seven weeks-Diagrammatic representations of these cross-sections are given in Figure 3. Some of the corresponding microradiographs are shown in Figures 4 to 8 . In Figure 3 the position of the remains of epiphysial bone and areas of active deposition of bone on the periosteal and endosteal surfaces are marked.
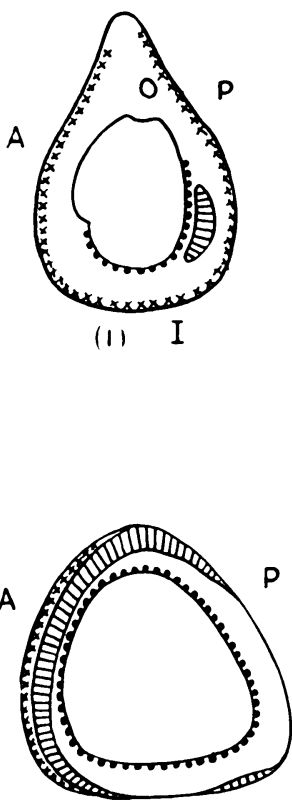

(13) I

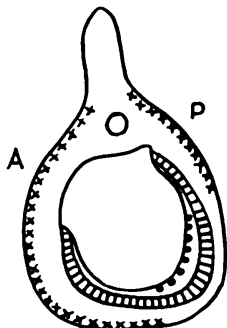

(5) I

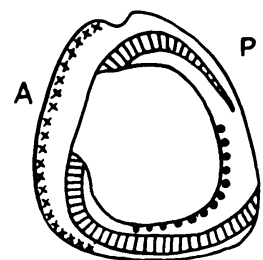

(8) I

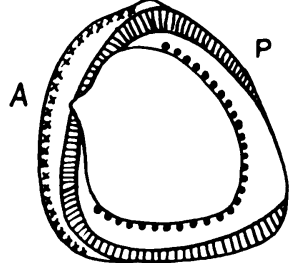

(ii) I

FIG. 3

$x \times \times \times \times \times \times x=$ Periosteal

IIIIIII)UIIIII = Epiphysial

.......... Endosteal

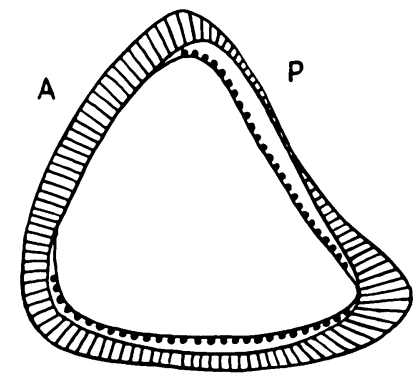

(22) I

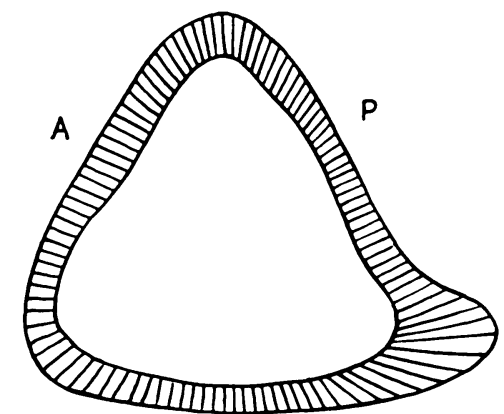

(25) I

Diagrammatic representations of the cross-sections of the tibia of a rabbit aged five to seven weeks. $A=$ anterior wall; $I=$ internal wall ; $P=$ posterior wall.

On the microradiographs of young rabbits these areas of deposition have a characteristic appearance. On the periosteal surface numerous capillaries are seen entering the bone, surrounded by areas with a low degree of calcification. On the endosteal surface the bone is trabecular and the surface is rendered irregular by marrow spaces around which calcification takes place. Examples of these are to be seen on the periosteal surface of the anterior wall and the lower half of the endosteal surface of the posterior wall (Fig. 5, section 8).

The uneven distribution of periosteal and endosteal bone formation is striking (Fig. 3). In the mid-shaft (section 1) there is periosteal growth practically all the way round and a few patches of endosteal deposition especially at the corner between the internal and posterior walls (hereafter called IP). In section 5) (Figs. 3 and 4) periosteal deposition predominates in the anterior wall and the band of epiphysial bone has been partly resorbed via the endosteal surface; there is also some deposition on the endosteal surface at IP. In sections 8 and 11 (Figs. 3 and 5)

rol. $37 \mathrm{~B}$, No. 2, MAY 1955 


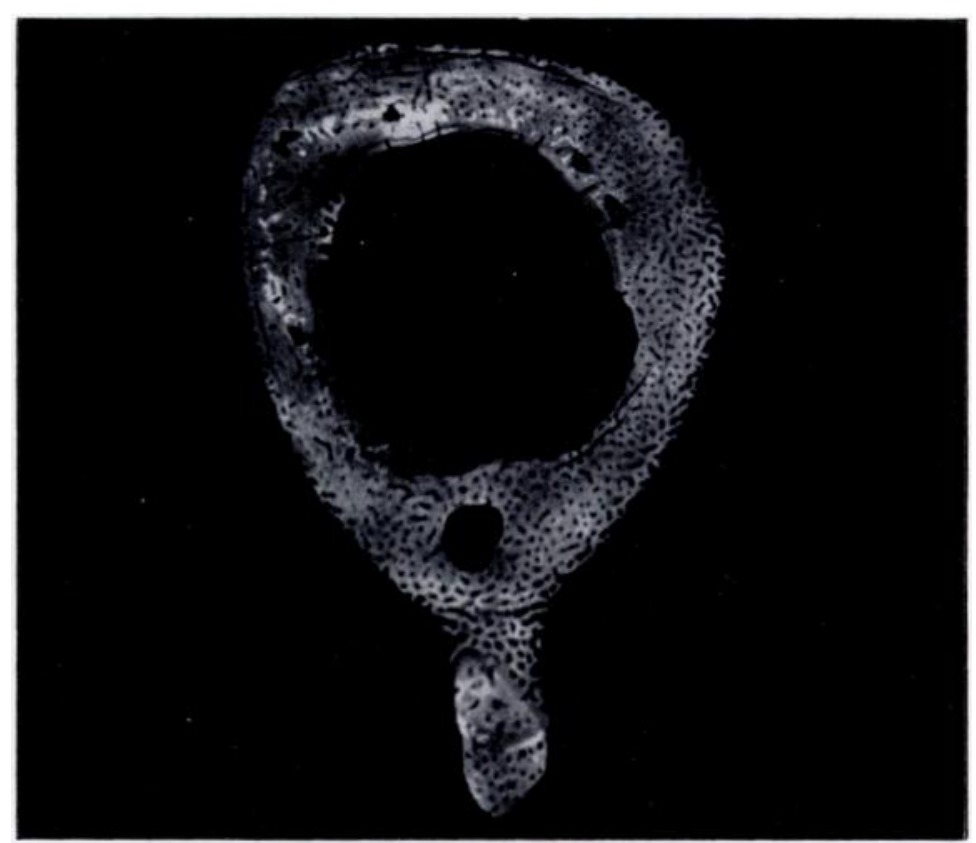

Fig. 4

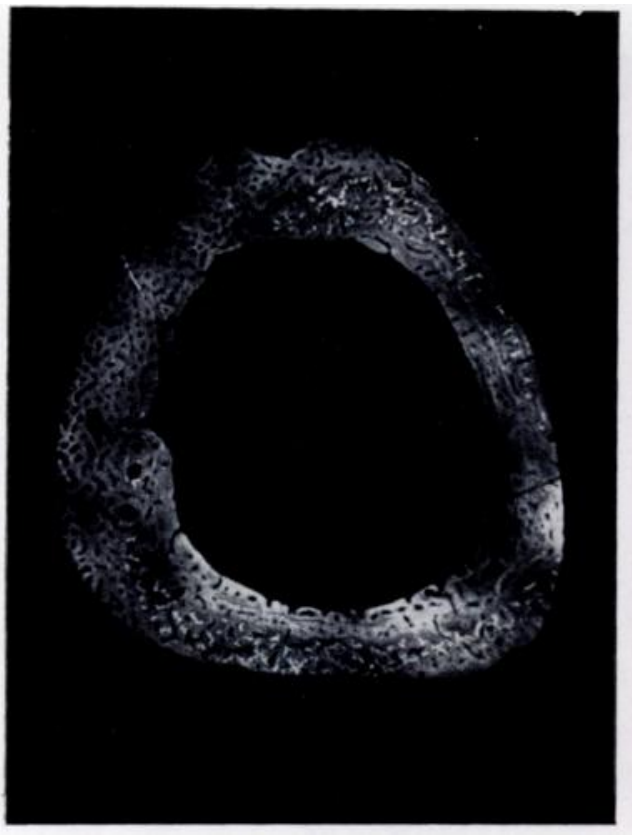

Fig. 5

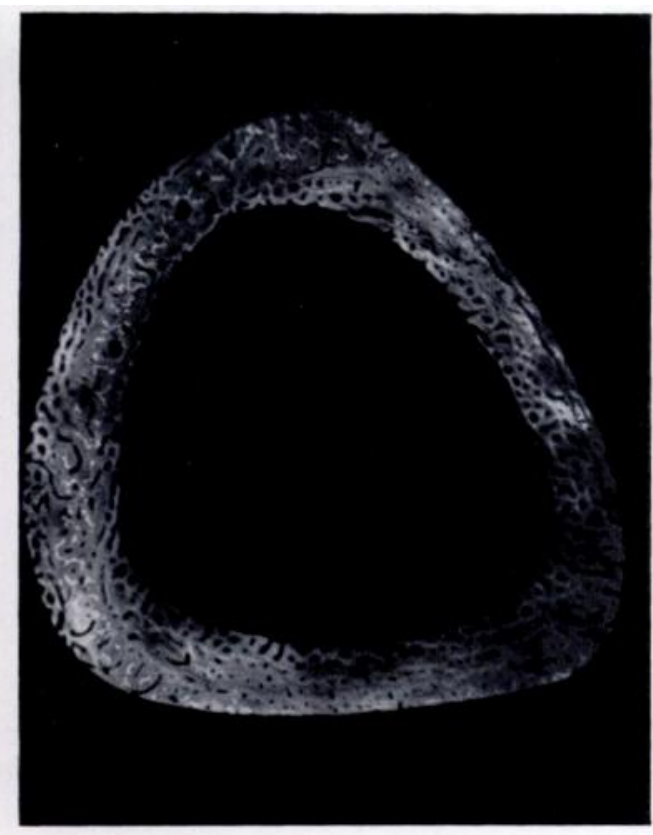

FIG. 6

Microradiographs of transverse sections of the tibia of a rabbit aged five to seren weeks. (.III - 14.) Figure 4-Section 5. Note the vascular appearance typical of young actively growing bone on periosteal surface of anterior wall and endosteal surface at corner IP. Note also the remains of epiphysial bone in posterior and internal walls. Figure 5-Section 8. Note growth on the periosteal surface of the anterior wall and increasing growth on the endosteal surface at corner IP: and the position of the band of epiphysial bone indicating its resorption on endosteal surface of anterior wall and periosteal surfaces of posterior and internal walls. Figure 6-Section 13. Note the growth taking place on entire endosteal surface, and the band of epiphysial bone largely in anterior wall which also shows periosteal growth. 


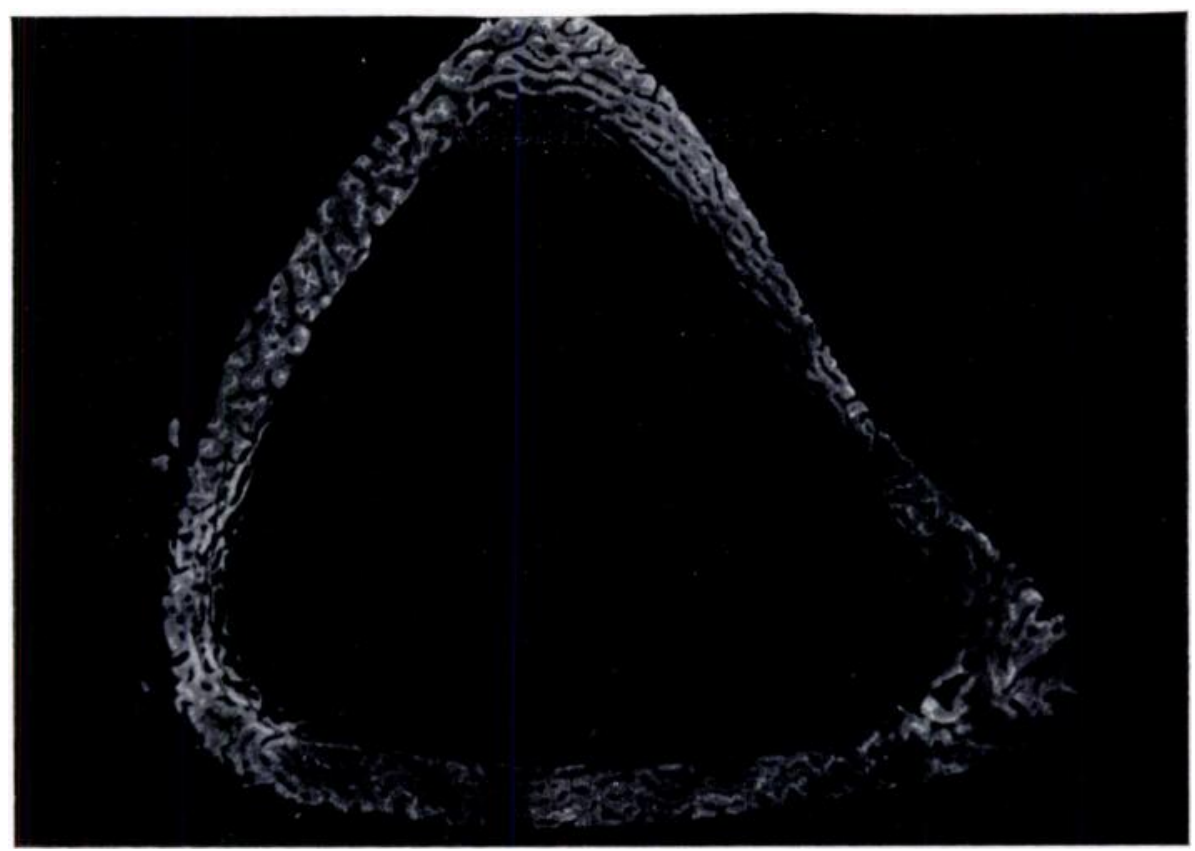

FIG. 7

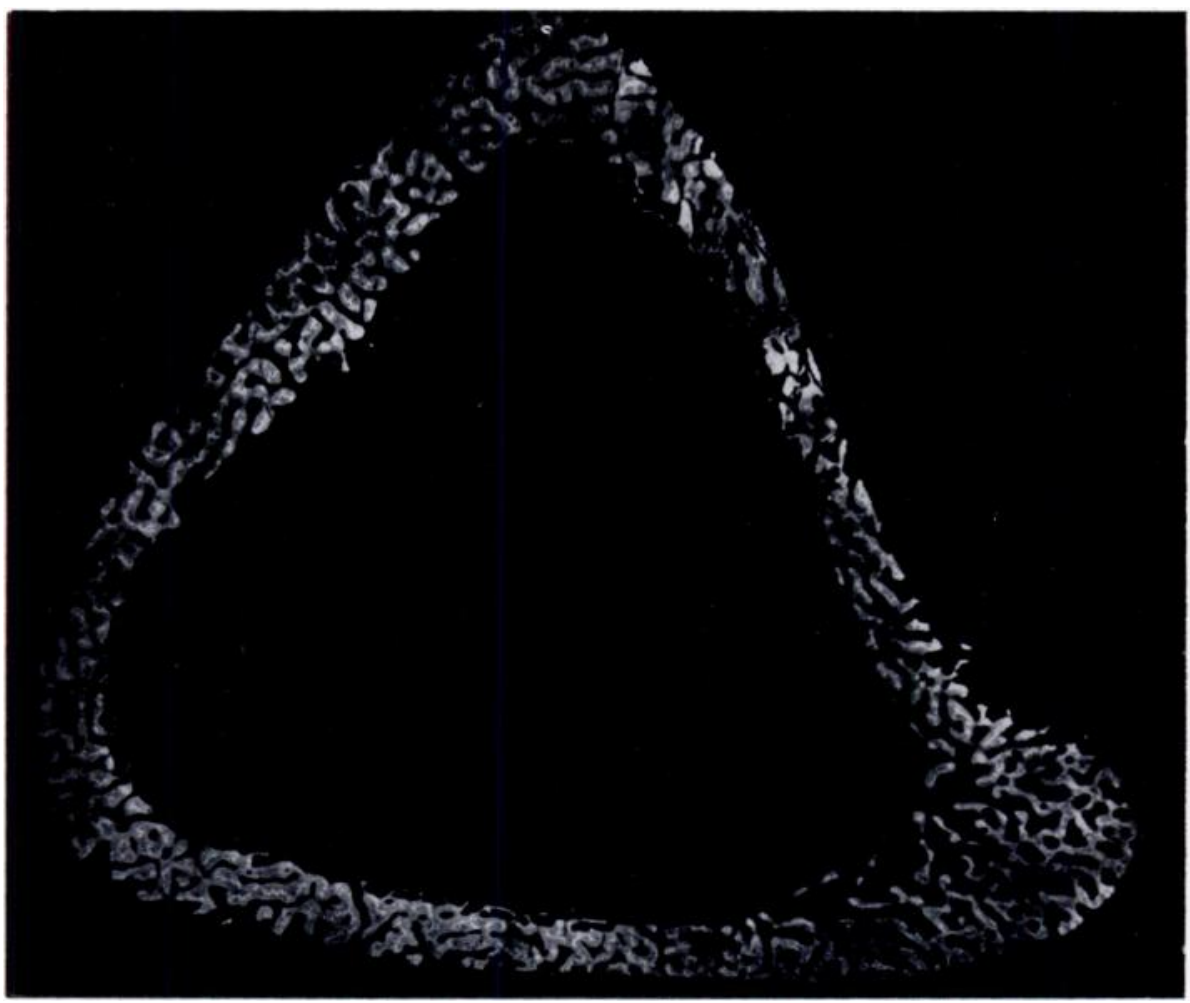

Fig. 8

Further sections from the rabbit's tibia shown in Figures 4 to 6 . ( 14.) Figure 7-Section 22. Note the endochondral bone remaining in anterior wall, and epiphysial bone resorbed on periosteal surface of posterior and internal walls and replaced by endosteal bone. Figure 8 Section 25. Note the presence of epiphysial bone in all walls. 
there is bone formation on the periosteal surface of the anterior wall with resorption on its endostcal surface; endosteal deposition now extends from IP along the surfaces of the posterior and internal walls while resorption takes place on the periosteal surfaces of these walls. In section 13 (Figs. 3 and 6) bone formation is taking place on the entire endosteal surface. Remnants of epiphysial bone now remain almost entirely in the anterior wall; and there is still evidence of periosteal deposition in this situation. Section 22 (Figs. 3 and 7 ) shows how the band of bone containing cartilage remnants-that is, bone formed in the region of the epiphysial plate, spoken of as epiphysial bone-remains in the anterior wall while it is quickly resorbed

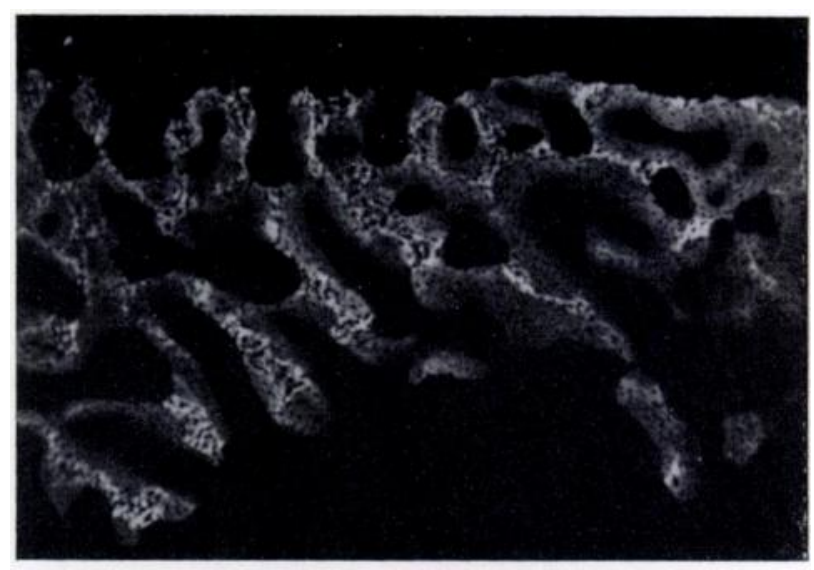

Fig. 9

Microradiograph showing epiphysial bone containing calcified cartilage and large cells. Part of corner between internal and posterior walls of section 26 of the tibia of a rabbit aged five to seven weeks. $(\cdot \mathbf{4 5}$.)

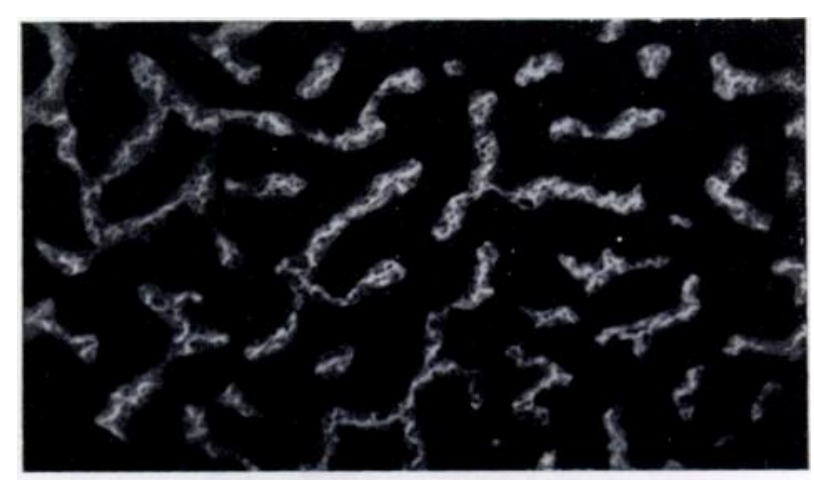

FIG. 10

Microradiograph showing epiphysial bone just below the epiphysial plate. Section 28 from the tibia of a rabbit aged five to seven weeks. $(\times 45$.)

via the periosteal surface on the posterior and internal walls and replaced by bone laid down on the endosteal surface. Section 2:5 (Figs. 3 and 8), which comes from just below the epiphysis, shows the presence of epiphysial bone equally in all three walls. Figure 9 illustrates detailed structure from corner IP in an adjacent section, and shows pieces of calcified cartilage containing large cartilage cells, embedded in new bone which has been formed adjacent to them. Figure 10 illustrates part of section $\mathbf{2 8}$, which is cut where the whole area of the cross-section is made up of epiphysial bone and demonstrates clearly that the bone adjacent to the calcified cartilage is less highly calcified than is this tissue. 
Serial transverse sections of the tibia of rabbits three and a half, seven and twelve months old-In our experiments the mid-shaft was taken as the geometrical middle of the bone. It is therefore unlikely that the mid-shaft of the weanling and the older animals will correspond preciscly, for it is known that the tibia does not grow equally from each end (Payton 1931 -32, Bisgard and Bisgard 1935, Gill and Abbott 1942) and also no two animals grow exactly alike. In fact, sections from a particular level in the weanling as marked in Figure 1 should be compared with those of a slightly lower level in the older animals. Because of growth in width the junction of the tibia and fibula is relatively higher in the older rabbits than in the weanling. A comparison of the first twenty sections of the weanling with those of the older rabbits shows that the position of cartilage remains in comparable sections in rabbits from all ages is very similar. On the whole, there are fewer cartilage remnants in the bones of the older rabbits, many of them having already been removed in the process of remodelling. The bone of the

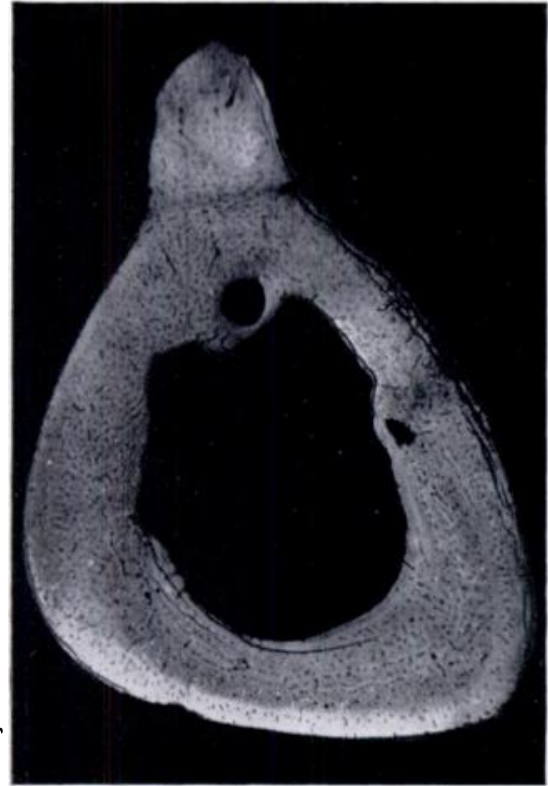

FIG. 11

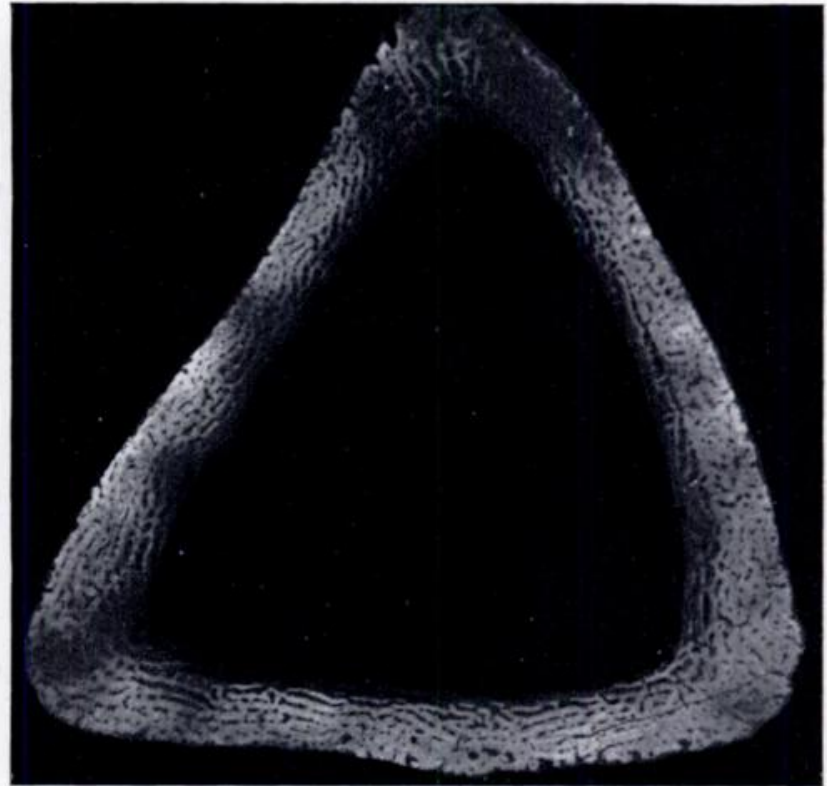

FIG. 12

Figure 11- Microradiograph of section 6 from the tibia of a rabbit aged seven months. Periosteal and endosteal bone is almost entirely non-Haversian. Note also the relatively low calcification of remains of epiphysial bone in internal wall. (. 12.) Figure 12-Microradiograph of section 34 from the tibia of a rabbit aged three and a half months. Note the vascular appearance of endosteal surface typical of active growth, and the eaten appearance of periosteal surface where endochondral bone has been resorbed. ( 12 .)

seven months and twelve months old rabbits is very similar and it is only necessary to show examples and describe that of the seven months old. This older bone is much more mature than the bone of the weanling or of the three and a half months old rabbits which is in an intermediate stage. This maturity is demonstrated in many ways. For example, the bone is thicker, the Haversian sustems and lacunae are smaller, giving it a more solid appearance, and it is more highly calcified. Moreover periosteal and endosteal bone is now almost entirely nonHaversian An example is shown in section 6 (Fig. 11) of the seven months old rabbit. The position of the band of old bone containing cartilage remnants which is still present in the interior of the cortex in this section can be compared directly with that in section 8 (Figs. 3 and 5 ) of the weanling. Note also that the band of epiphysial bone in Figure 11 is of a lower degree of calcification than the more recent bone formed on the periosteal and endosteal surfaces. Higher up, in sections 14 to 23 approximately, remains of a band of epiphysial bone can be found in the anterior wall, but not in other walls at this level. This finding is in agreement with the results 


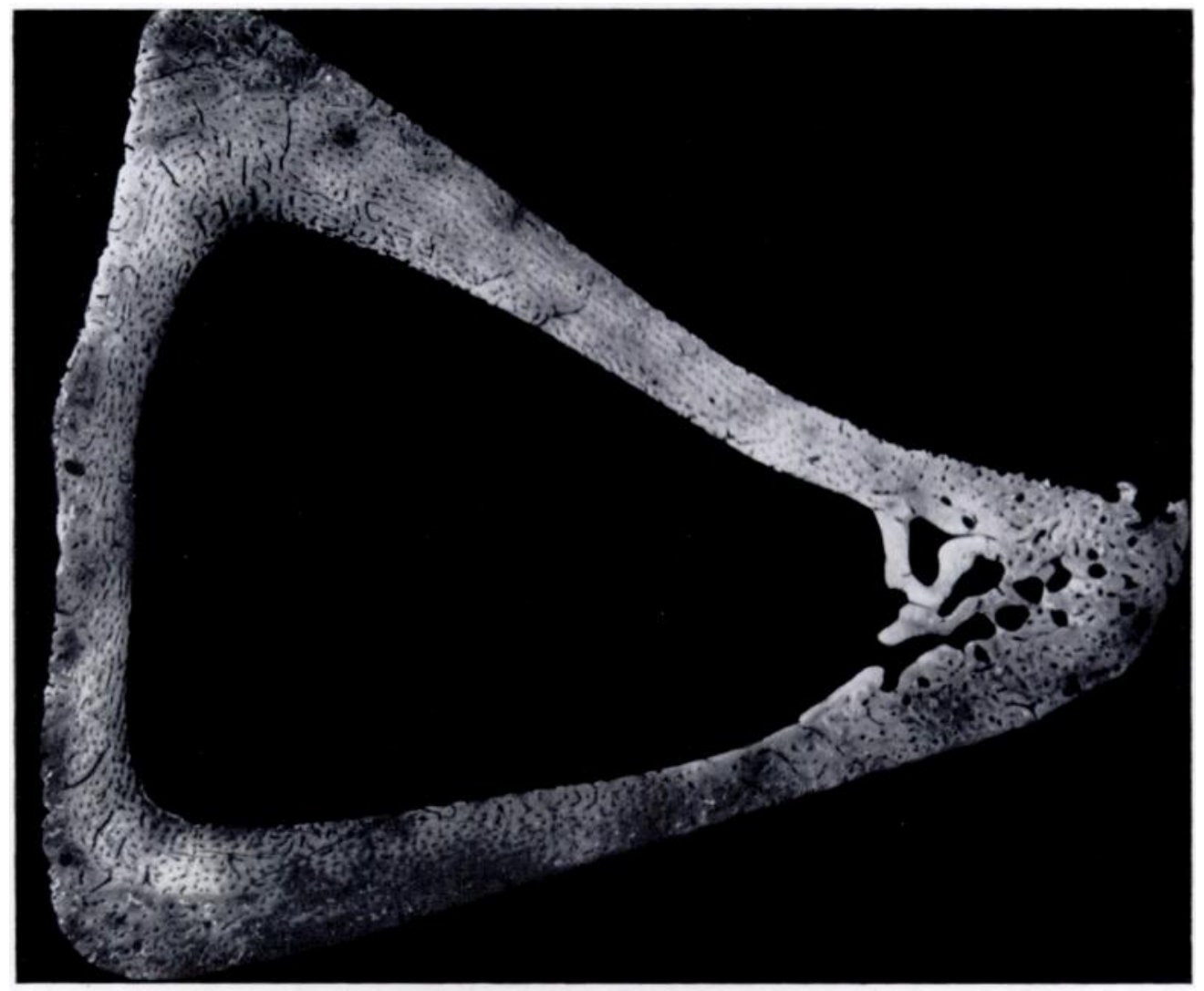

FIG. 13

Microradiograph of section $\mathbf{4 7}$ from the tibia of a rabbit aged seven months. Note the band of endosteal bone, the remains of epiphysial bone on periosteal surface; and the cartilage remains in II? $(\cdot 14$.)

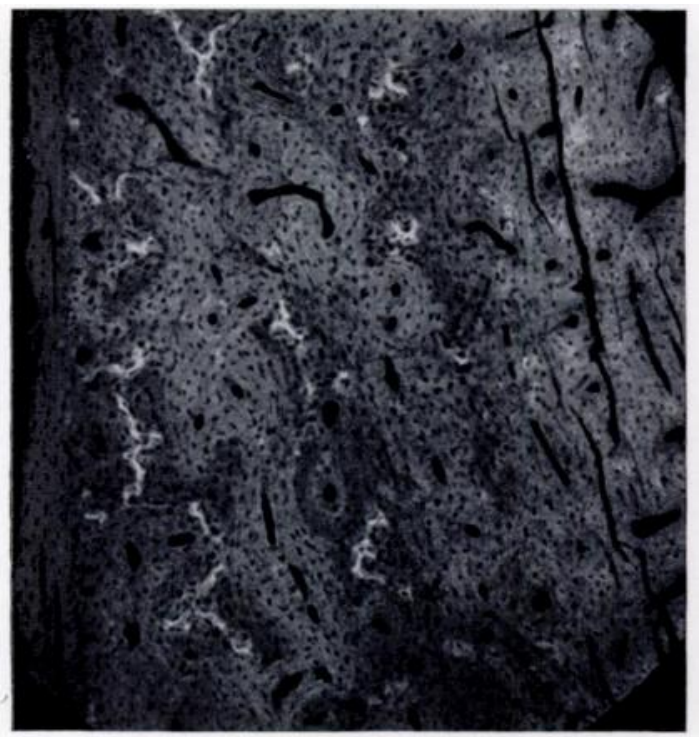

Fig. 14

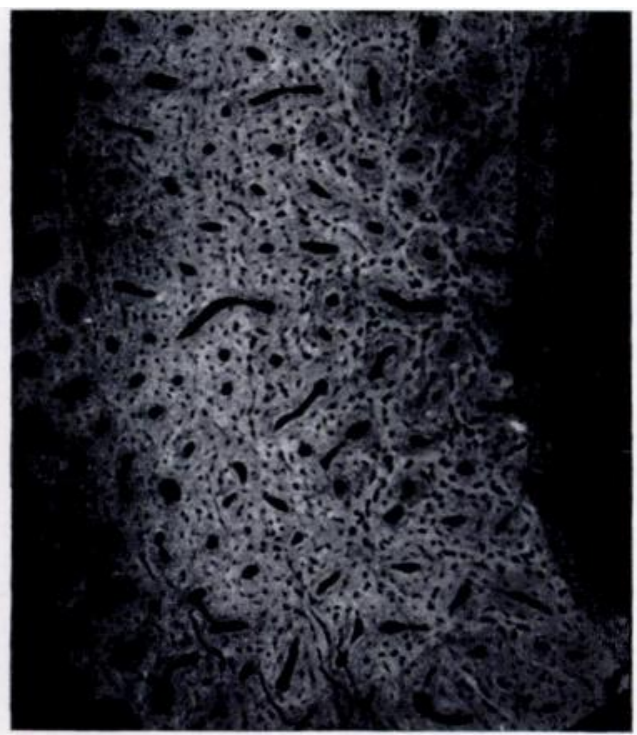

FIG. 15

Figure 14-Microradiograph showing epiphysial bone at corner between anterior and internal wall of section 42, from the tibia of a rabbit aged seven months. $(\times 45$.) Figure 15-Microradiograph of part of section 1 from the tibia of a rabbit aged five to seven weeks. Note periosteal bone containing small lacunae, and bone containing small evenly calcified Haversian systems among more highly calcified bone with large lacunae. $(\times 40$.

THE JOURNAL OF BONE AND JOINT SURGERY 
obtained in the weanling rabbit and becomes of importance later when the autoradiographs are considered.

As can be seen from Figure 1 , the first twenty sections comprise approximately the Clindrical part of the shaft of the adult animal. Above section 20 - that is, during the period of growth of the metaphysial funnel or from the age of five to seven weeks onwards, transverse growth is of a different character. It is, in fact, practically pure apposition on the endosteal surface with resorption of the epiphysial bone on the periosteal surface. However, sections from just beneath the epiphysis show that deposition of bone during this period is also uneven, in that there is definite evidence that these processes are still more rapid on the surfaces of the posterior and internal walls than on those of the anterior wall. A trpical example of endosteal deposition and periosteal resorption is seen in section 34 (Fig. 12) of the three and a half months

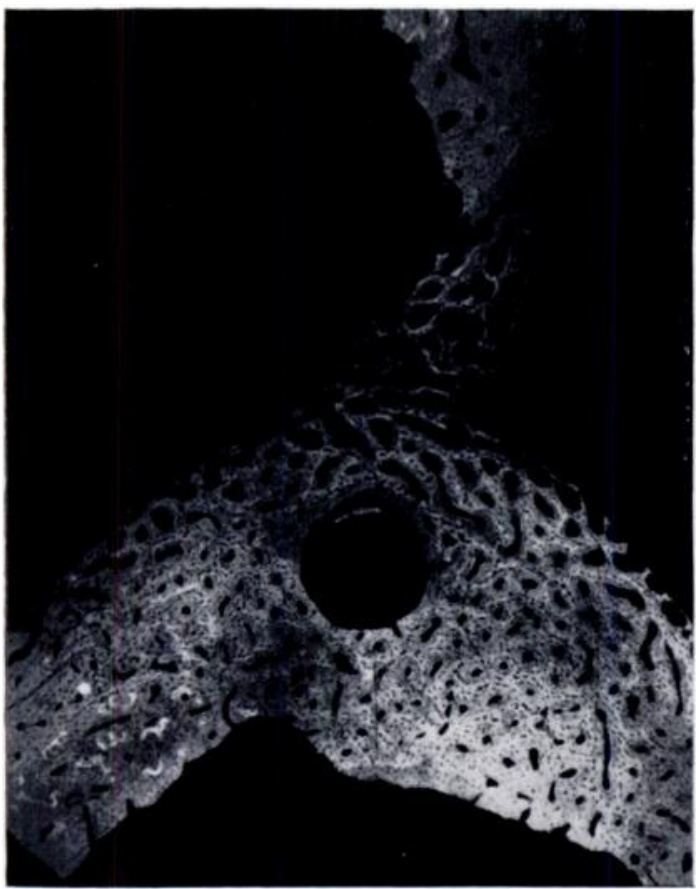

Fig. 16

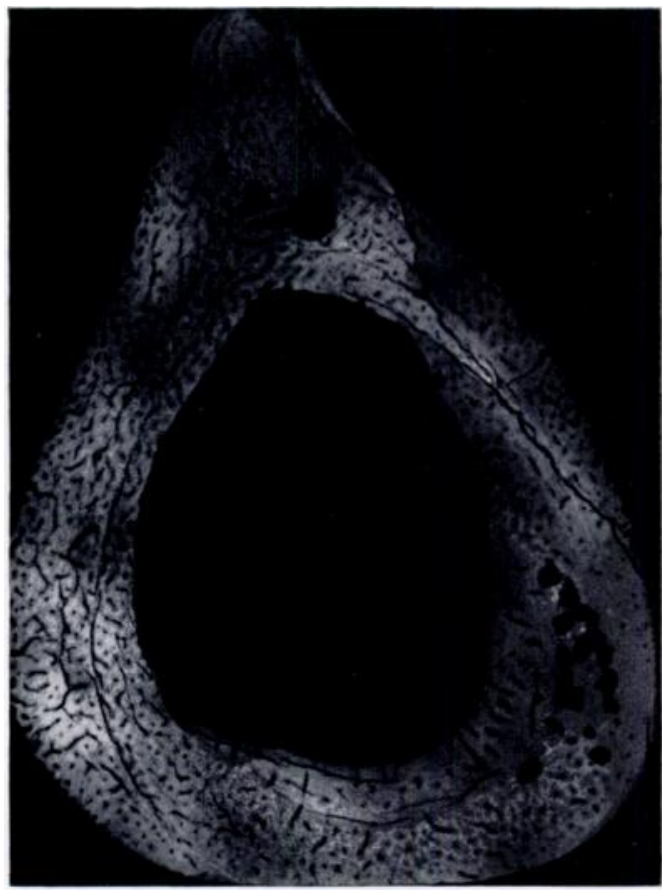

Fig. 17

Figure 16 - Microradiograph of junction of tibia and fibula. Section 6 from a rabbit aged five to seven weeks. Note the large lacuna in the bone at the junction. (.30) Figure 17-. Nicroradiograph of section 3 from the tibia of a rabbit aged three and a half months. Note area of resorption carities and building sites remodelling band of old bone. $(\cdot 17$.

old rabbit, which shows, especially at corner IP, numerous marrew spaces with a low degree of calcification on the endosteal surface, and an eaten appearance on the periosteal surface indicating resorption. Section 47 (Fig. 13) of the seven months old rabbit also shows a distinct band of endosteal bone and remains of epiphysial bone which are in the process of being resorbed on the periosteal surface. This section has the typical shape of the cross-section of the tibia of the adult animal at this level. Corner IP is extended and contains many pieces of cartilage, within which are embedded large cartilage cells similar to those shown in Figure 9. There is always some epiphysial bone at each of the other corners (Fig. 14). The bone adjacent to the calcified cartilage is of a lower degree of calcification than the calcified cartilage and the intervening Haversian systems.

Many other details may be observed on the microradiographs. It is seen that old bone (that is, bone formed early in the life of the animal) contains much larger lacunae than more 
recently formed bone. For example, in sections from the mid-shaft of the weanling, such as that shown in Figure 15, the bone of the deep part of the cortex has large lacunae, while in the more recently formed bone on the outer surface these are smaller (Fig. 15). The origin of this band of bone with large lacunae is being further studied. Similar large lacunae are also seen in epiphysial bone, in particular in the lowly calcified bone which is adjacent to highly calcified cartilage (Fig. 14), and in many other places, particularly the junction of the tibia and fibula (Fig. 16). In all the examples noted very active bone formation was taking place at the time the bone was formed, and it is possible that the cells are larger for this reason. Remains of these large cells can be seen in seven months old and twelve months old bone. Compare, for example, the cells in the band of old bone in Figure 18 with those in more recently formed periosteal bone.

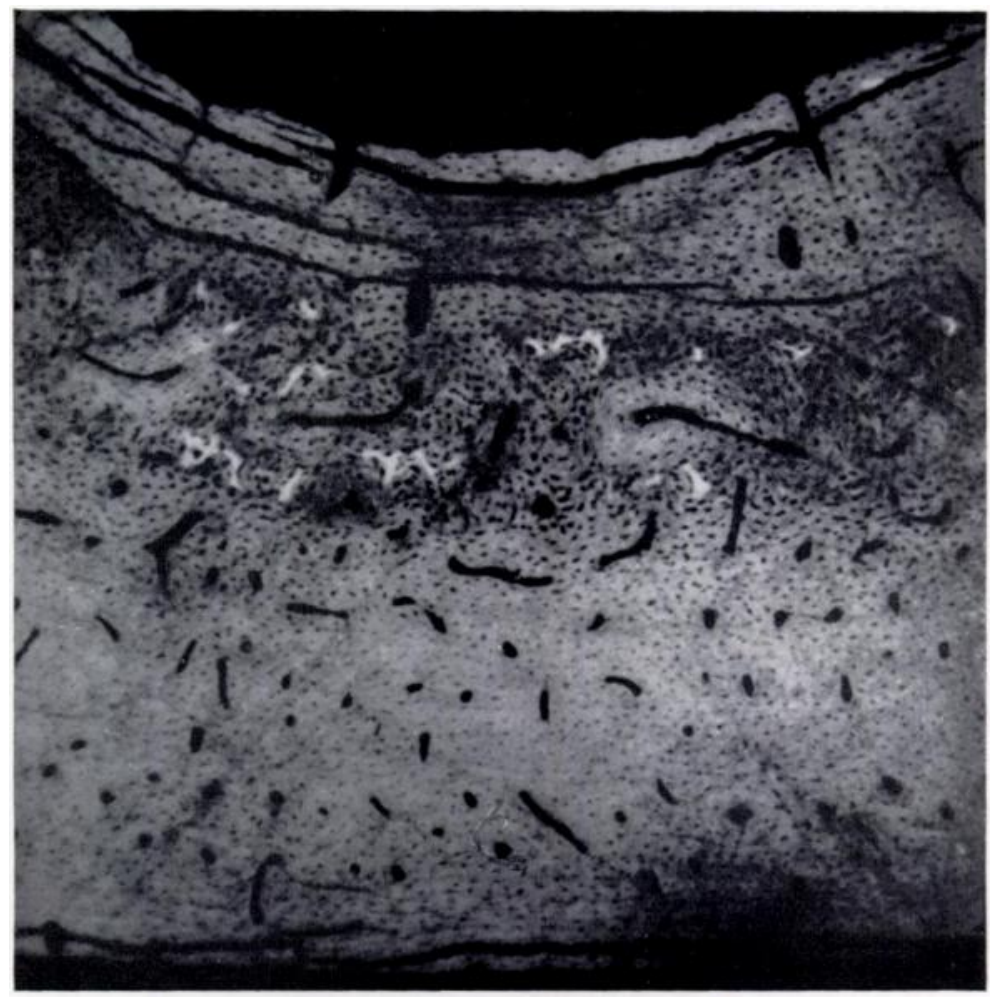

Fig. 18

Microradiograph of part of section 1 from the tibia of a rabbit aged seven months. Fote highly calcified Haversian systems in region of epiphysial bone, and highly calcified periosteal bone. $(-85$.

There are a considerable number of resorption cavities and building sites in animals of all ages, illustrating the continual remodelling of bone. Resorption cavities, building sites and Haversian sustems are closely related to one another anatomically and develop one from the other (Tomes and Morgan 18533, Petersen 1930, Amprino 19:52, Jowsey et al. 195336). In the microradiograph the typical resorption cavity appears as a large hole with an irregular boundary, the building site as a large or small hole with surrounding bone showing variable degrees of calcification and the Haversian system, which is a completed osteone, as a small hole with an even degree of calcification around it (Fig. 17). The distribution of resorption cavities and building sites was almost entirely associated with areas containing remains of calcified cartilage and old bone (Figs. 4 to 6). A typical example of this is the area of resorption cavities and building sites in the posterior wall (Fig. 17) demonstrating the removal and replacement of the band of old bone in the mid-shaft of this rabbit. The latter is characterised by the large 
cells in the bone between the Haversian systems (see above). Figure 18 is another example of remodelling taken from the internal wall of section 1 of the seven months old rabbit. Note here the fully calcified new Haversian system, which is more highly calcified than the band of old bone in which it is situated.

\section{AUTORADIOGRAPHS}

Previous work on the deposition of radioactive strontium and calcium in bone, based on a study of autoradiographs prepared from both longitudinal and cross-sections, suggests that both isotopes are incorporated into areas of active bone formation (Kidman et al. 1952, Jowsey et al. 1953b, Lacroix 1953). The autoradiographs made from sections of bones of rabbits in the present series confirm both this hypothesis and the conclusions drawn from the microradiographs. The detailed results from three rabbits can be considered as representative of the findings in all the animals examined and included in Table I. Two of these were injected when weanlings and killed eight weeks and twenty-four weeks after injection. The third was injected when six months old and killed seventeen days after injection.

Rabbits injected as weanlings and killed eight weeks and six months after injectionThe ${ }^{90} \mathrm{Sr}$ retained in the weanling killed eight weeks after injection showed a similar pattern to that retained in the weanling killed twenty-four weeks after injection.

Section 6 (Fig. 19) of the rabbit killed twenty-four weeks after injection shows the position in the shaft of ${ }^{90} \mathrm{Sr}$ taken up on the periosteal and endosteal surfaces at the weanling stage. It has exactly the position expected when compared directly with the microradiograph of section 8 of the weanling (Figs. 3 and $\tilde{5}$ ). Of course, when the rabbit, from which the section shown in Figure 19 was taken, was a weanling, the tibia and fibula had not joined: if they had the band of periosteal uptake would have been different in position and would have appeared like that in Figure 20. The site of entry of the artery in section 8 (Fig. 3) in the centre of the band of periosteal growth corresponds to the position of the artery in the middle of the band of reaction in Figure 19. Further periosteal deposition results in junction with the fibula. A little farther up the shaft (section 11, Fig. 21) the autoradiograph shows a band of radioactivity corresponding to endosteal uptake. It is as expected when compared with section 13 of the weanling (Figs. 3 and 6 ). In the rabbits killed eight weeks after injection autoradiographs of some sections from this level show evidence of uptake on the periosteal surface of the anterior wall, which is also to be expected (see section 13, Figs. 3 and 6). There is also evidence that this is in the process of being resorbed and is thus not visible in rabbits killed six months after injection. Another example from this rabbit is section 1 which compares directly with section 1 of the weanling (see Fig. 20). In this section there are interesting examples of closed Haversian systems containing ${ }^{90} \mathrm{Sr}$ which are fully calcified in the microradiograph. These were presumably of low calcification at the time of injection.

Typical uptake on the endosteal surface has the appearance of a necklace because in the weanling the strontium was laid down round the large marrow spaces included by trabecular bone which were present at the time of injection (Fig. 22). Typical uptake on the periosteal surface also occurs in relation to the vascular supply, which in this case is dependent on periosteal capillaries and therefore presents a slightly different appearance (Fig. 23). This uptake occurring in relation to the blood vessels and sinuses on the periosteal and endosteal surfaces is typical of the young and actively growing rabbit. As will be seen later, uptake on these surfaces in the older rabbit is different.

The autoradiograph of section 20 (Fig. 24) of the weanling killed twenty-four weeks after injection shows a striking example of uptake in areas of highly calcified cartilage and the bone adjacent to it. At the time of injection this was presumably in the region of the epiphysial plate, which is known to take up strontium very readily in the weanling rabbit (Jowsey et al. 1953a). Tissue showing this type of uptake is only evident in the anterior wall, the epiphysial bone laid down in the posterior and internal walls having later been resorbed via the periosteal surface and replaced by bone laid down on the endosteal surface (section 22 of the weanling in

VOL. $37 \mathrm{~B}$, NO. 2, MAY 1955 


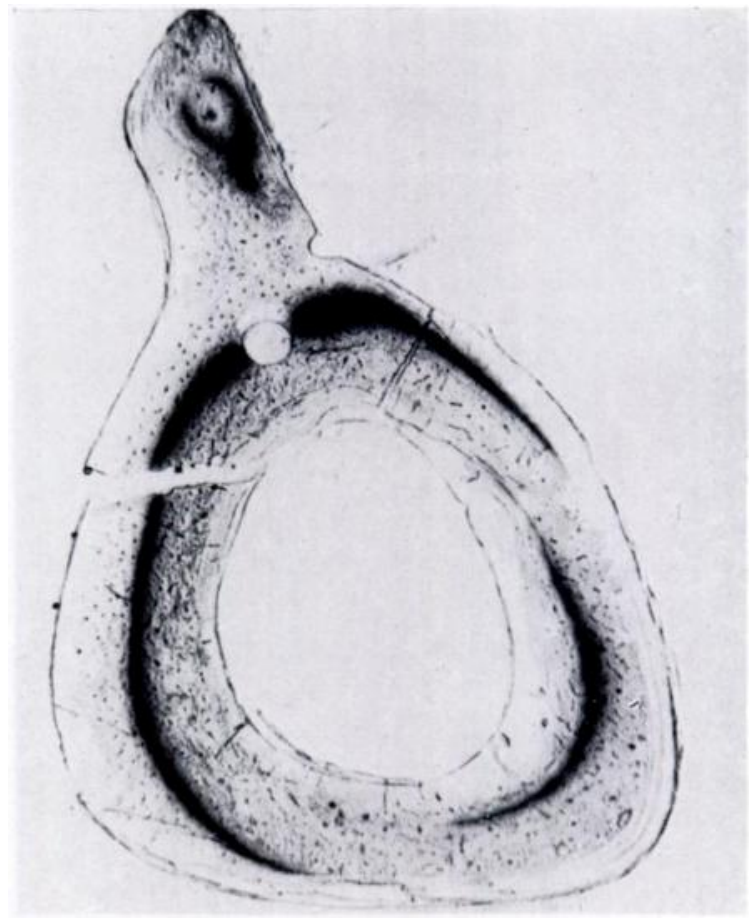

FIG. 19

Autoradiograph left on section of the tibia of a rabbit injected at five to seven weeks old and killed twent $y$-four weeks later. Note concentrated reaction in the remains of periosteal bone in the anterior wall and endosteal bone in the posterior wall. $(\cdot 12$.)

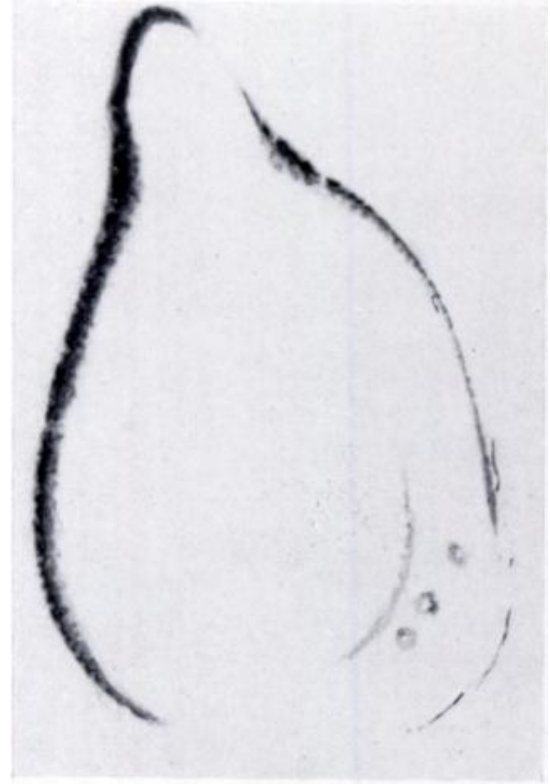

FIG. 20

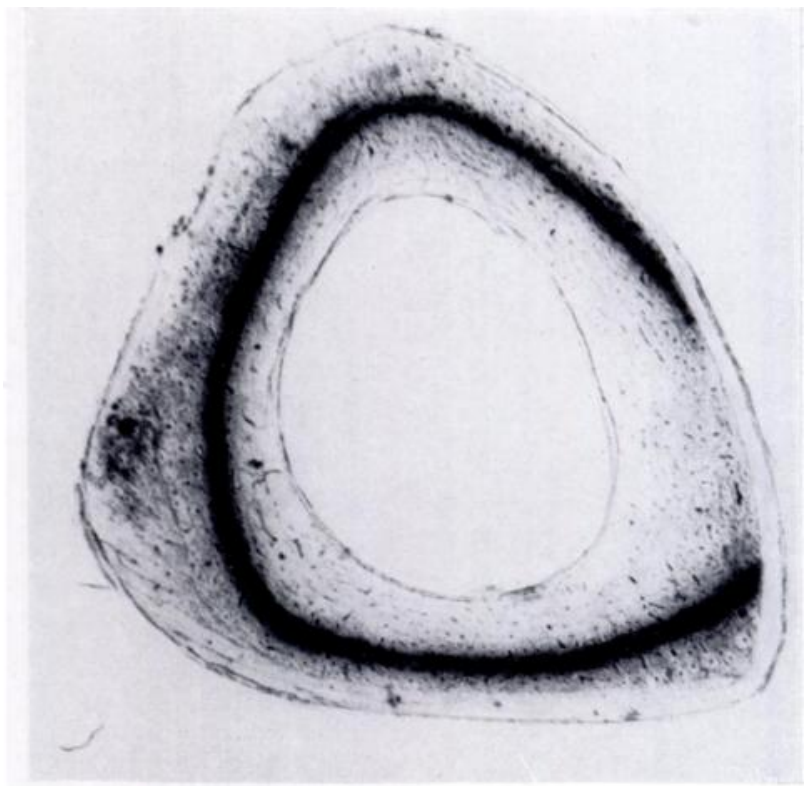

FIG. 21

Figure 20-Autoradiograph removed from section 1 of the tibia of a rabbit injected at five to seven weeks and killed eight weeks later. Note heavy reaction in remains of old periosteal bone, reaction in remains of endosteal bone, and reaction round the outer rings of fully formed Haversian sections. (. 10.) Figure 21Autoradiograph left on section 11 of the tibia of a rabbit injected five to seven weeks old and killed twent $\mathrm{v}$ four weeks later. Note the concentrated reaction in the remains of old endosteal bone. $(\because 12$. 
Figs. 3 and 7). There is no significant ${ }^{90} \mathrm{Sr}$ uptake in sections above about level $\mathbf{2 0}$, presumably because this bone was formed after the ${ }^{90} \mathrm{Sr}$ level in the blood had fallen appreciably. For the same reason there is also no uptake in many Haversian systems which show low calcification on the microradiographs.

It should be mentioned that the bones of this rabbit grew much less after the weanling stage than the normal seven months old rabbit. This was due probably to the heavy deposit of radioactive $\mathrm{Sr}$ in the calcified cartilage of the weanling, for the microradiographs show some evidence of disorder in the bone formed above the weanling level. Further experiments are at present in progress to investigate these effects.

Rabbit injected at the age of six months and killed seventeen days after injectionAutoradiographs from certain sections show examples of the uptake of strontium in building sites which are seen to be lowly calcified on the microradiographs. These building sites are situated within the band of old bone which was formed early in the life of the animal. Old bone includes both the epiphysial bone which was laid down beneath the epiphysial plate and the

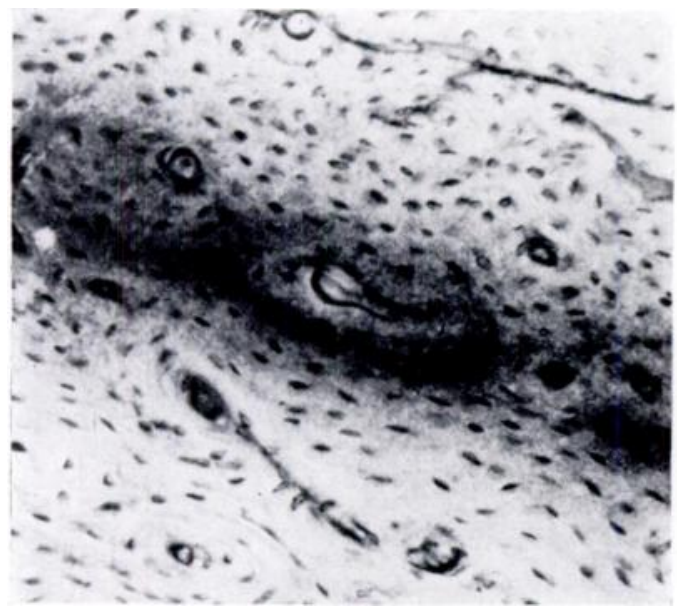

FIG. 22

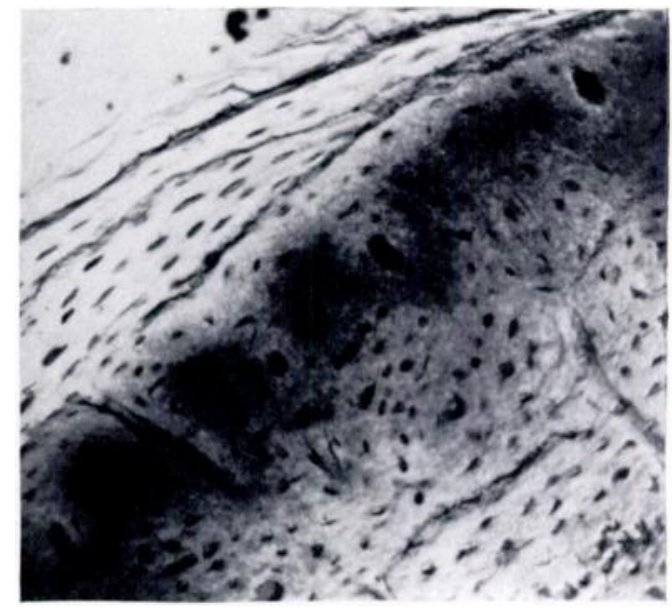

FIG. 2:3

Figure 22-Autoradiograph left on section, illustrating characteristic uptake of endosteal surface in actively growing tibia. Rabbit five to seven weeks old at time of injection, killed eight weeks later. Note the new bone laid down on that originally taking up ${ }^{90} \mathrm{Sr}$. (140.) Figure 23-Autoradiograph left on section, illustrating characteristic uptake on periosteal surface in actively growing tibia. Rabbit five to seven weeks old at time of injection, killed eight weeks later. Note the new bone laid down on that originally taking up ${ }^{90}$ Sr. $(\times 140$.

band of Haversian bone with large lacunae found in the mid-shaft. Figure 2:5, which is taken from level 8, is a good example of remodelling of the band of old bone in the anterior wall. It is comparable with about section 11 of the weanling (Fig. 3). Section 16 (Fig. 26 ) is an example of the remodelling of the calcified cartilage which has remained in the anterior wall at this level. There is little growth in width of the cylindrical part of the shaft at this age. There are only patches of uptake to be seen on the periosteal and endosteal surfaces. In the metaphysis there is still considerable uptake on the endosteal surface (section 40, Fig. 27). Detail from this section (Fig. 28) shows that the growth is non-haversian, which is characteristic of endosteal and periosteal growth in older animals. Uptake in calcifying cartilage at corner IP also occurs (Fig. 27).

\section{DISCUSSION}

The facts recorded here may be discussed under two headings, one concerned with the details of tibial growth in the rabbit, the other with the relevance of the observations to general problems of bone growth and pathology.

Bone growth in the upper half of the tibia-Some interesting features concerning the growth

vOL. 37 B, NO. 2, MAY 1955 
of the proximal half of the tibia have been observed. The growth in length of the bone occurs at the epiphysial plate by the normal process of endochondral ossification. More by chance than design the tibia at five to seven weeks old was studied and the length of the tibia at this age is approximately the length of the cylindrical part of the shaft of the adult rabbit. The transverse growth of this part occurs by the apposition of bone on both the periosteal and endosteal surfaces in a characteristically uneven manner which has approximately the same pattern throughout the period up to seven months. This also results in the retention of epiphysial bone within part of the walls at various levels. The transverse growth of the metaphysial funnel occurs by apposition of bone on the endosteal surface and resorption of the epiphysial bone on the periosteal surface. These processes are also uneven, in that they take place more rapidly on the surfaces of the posterior and internal walls than on those of the anterior wall.

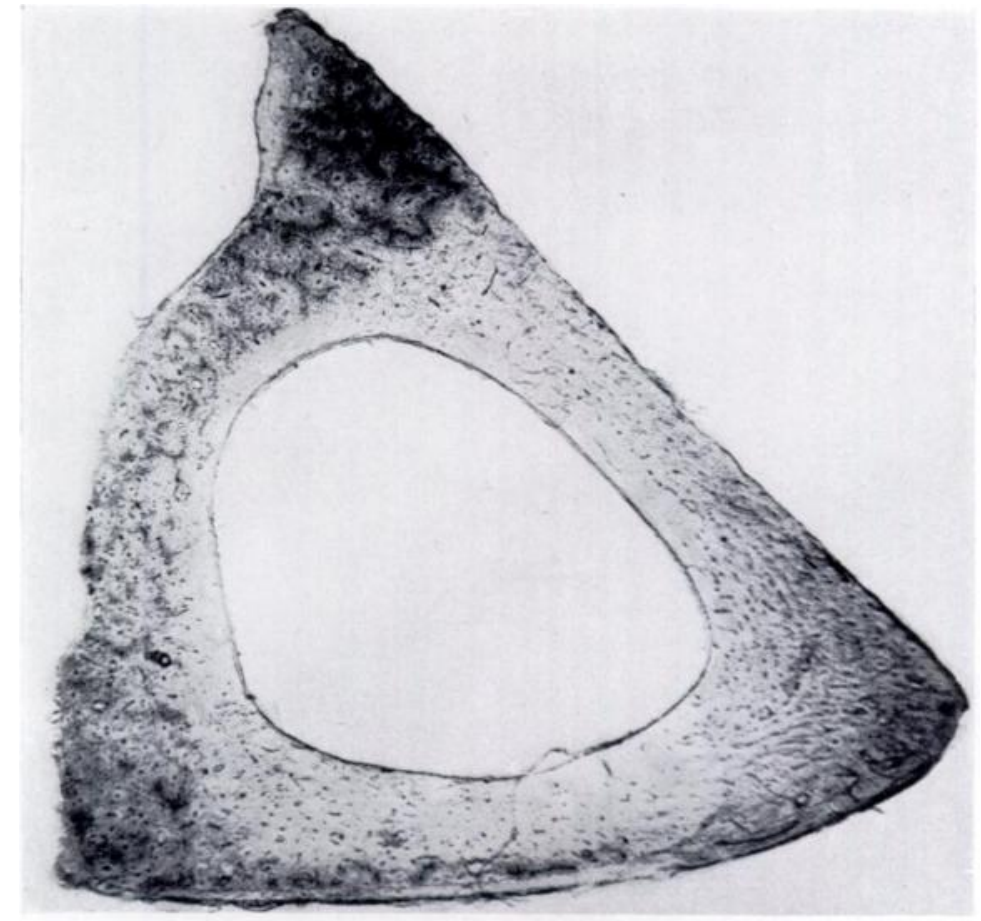

Fig. 24

Autoradiograph left on section 20 of the tibia of a rabbit injected at five to seven weeks and killed twenty-four weeks later. Note the heav reaction in the epiphysial bone in the anterior wall, particularly in remnants of calcified cartilage. $(\times 12$.)

This uneven growth on different walls was first noted by Duhamel (1743) using the madder technique.

The results described can be presented diagrammatically (Fig. 29). The Figure represents a longitudinal section through the middle of the anterior and posterior walls and demonstrates growth before seven months. The heavy broken lines show the position of the calcified cartilage remnants in the walls. A careful comparison of this with a previous macroscopic autoradiograph of a similar longitudinal section of the tibia of a rabbit injected as a weanling and killed six months later (Fig. 30) (Jowsey et al. 1953a) shows that the present results are in entire agreement with this work and provides a clear explanation of the localisation of ${ }^{90} \mathrm{Sr}$ shown on this autoradiograph. The heavy deposition at $(x)$ in the anterior wall is mainly due to the retention of the strontium in the calcified cartilage of epiphysial bone which was being formed at the time of injection (Fig. 24). As seen earlier, epiphysial bone is retained in this wall while it is 


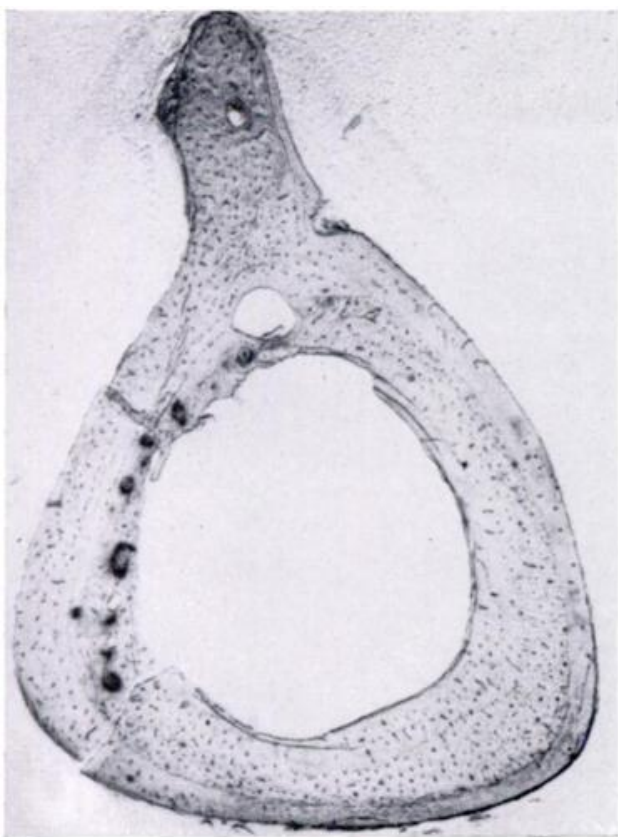

Fig. 25

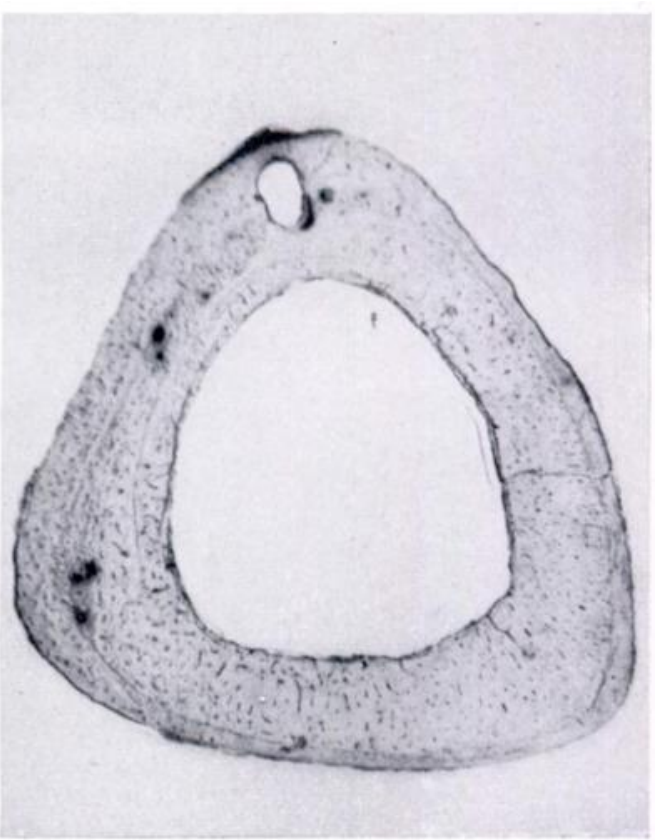

Fic. 26

Figure 25 - Autoradiograph left on section 8 from the tibia of a rabbit injected when six months old and killed seventeen dass later. Note the heary reaction round building sites in the anterior wall. (. 11.) Figure 26 - Autoradiograph left on section 16 from the tibia of a rabbit injected when six months old and killed seventeen days later. Note the heav reaction around building sites in the anterior wall, and traces of reaction in patches of periosteal bone. $(.11$.)

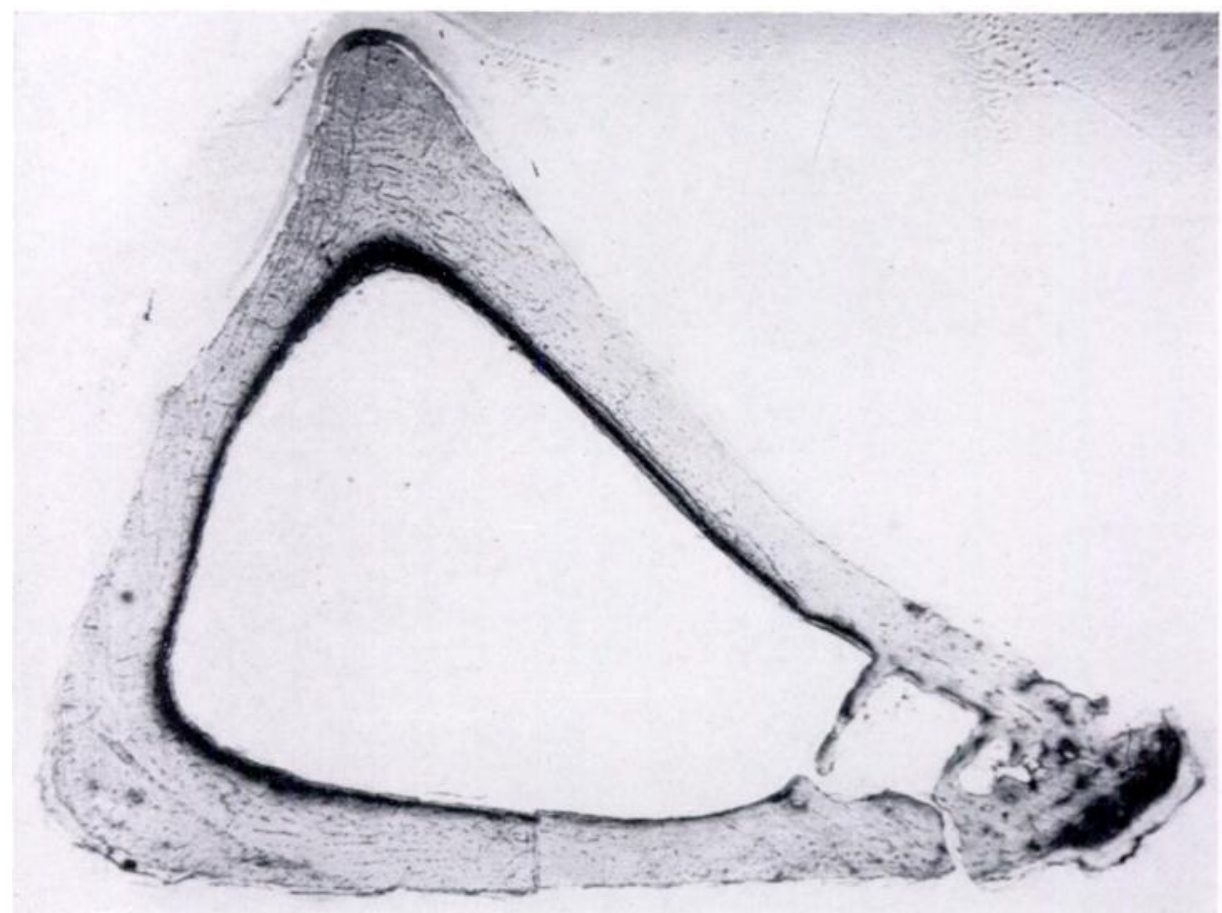

Fili. 27

Autoradiograph left on section 40 from the tibia of a rabbit injected when six months old and killed seventeen days later. Fote the heav reaction in endosteal bone and in calcifying cartilage at II'. ( . 11.)

ํ.. $37 \mathrm{~B}$, No. 2, NAY 1955

L 
quickly resorbed from the posterior and internal walls at this level (section 2:2 of weanling, Figs. 3 and 4). At $y$ the anterior wall shows lines of uptake on both periosteal and endosteal surfaces (compare with section 13 of weanling, Figs. 3 and 4). The patches between the endosteal and periosteal lines are probably due to uptake in building sites which are known to be remodelling epiphysial bone even in young rabbits. At $y$ in the posterior wall there is a line of endosteal uptake which ends abruptly. This is because endosteal deposition is rapid on this wall, especially higher up where endosteal bone laid down when the animal was a weanling has been resorbed via the periosteal surface six months later. (See section 11 of the rabbit injected as a weanling killed six months later, Fig. 20, which is comparable with about level 15 of the weanling.) At $z$ there is very active deposition on the periosteal surface of the anterior wall, and lines of endosteal and periosteal growth on the posterior wall with remodelling of the

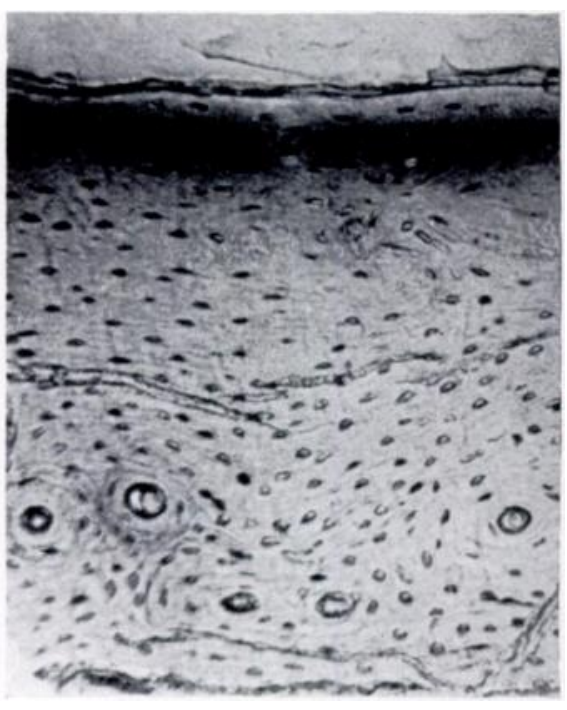

Fig. 28

Autoradiograph illustrating characteristic uptake on periosteal surfaces of tibia in rabbit six months old at time of injection, killed three weeks later. $(\times 140$. epiphysial bone retained between them (compare with section 5 of the weanling, Figs. 3 and 4 ).

It is clear from Figure 29 that the axis of growth is slightly displaced from the bone axis. This is because the tibia is not symmetrical about its longitudinal axis. It is in fact flatter and less curved on its anterior wall. This difference between the growth axis and the bone axis which is due to the unique shape of the tibia accounts for the unevenness of transverse growth in both the shaft and the funnel.

These results are in agreement with the general principle of transverse growth, namely endosteal apposition in the metaphysis and periosteal apposition in the shaft. They also demonstrate in which region of the adult rabbit tibia remnants of highly calcified cartilage may be found. Animals injected when the epiphysis is at a particular level will incorporate ${ }^{90} \mathrm{Sr}$ in the calcifying cartilage which remains at this level and retains it for a long time. The existence of resorption cavities and building sites which might have been expected from theoretical considerations of bone remodelling has been recognised before, but the present work demonstrates their situation and the contribution they make to the changing structure of developing and adult bone.

Relevance to general bone growth and pathology-The extremely variable pattern of bone structure within one long bone, depending both upon age and the anatomical level at which the bone is examined, has already been emphasised by Amprino and Bairati (1936) in the case of the human femur, and is well illustrated by the preceding observations in the tibia of the rabbit. On the other hand the similarity of the picture seen at any one anatomical level of the tibia in animals of the same age was striking. It is thus clear that in assessing the abnormality of bone structure in pathological material it is necessary to compare sections with those taken at the same anatomical levels from control normal animals of the same age and species. Individual pathological specimens must be interpreted with caution and the findings in one species or in one bone cannot be transferred to a different one.

Previous papers on the uptake of radioactive strontium (Kidman et al. 1952, Jowsey et al. $1953 a, 1953 b$ ) have emphasised that this occurs almost entirely in areas of active bone formation. This finding is confirmed by the more detailed histological studies described here. An area of bone which once incorporated ${ }^{90} \mathrm{Sr}$ in concentration retains that ${ }^{90} \mathrm{Sr}$ unless it is removed by resorption in the normal process of bone growth and remodelling. The real hazard of ingested radioactive strontium in bone is dependent on its localised concentration. The possible part 
played by a diffuse uptake throughout the bone dependent probably upon ionic exchange on the appetite crystal surfaces (Neuman and Weikel 1954), though of extreme interest from the point of view of general mineral metabolism, is probably not of importance so far as radiation hazards are concerned.

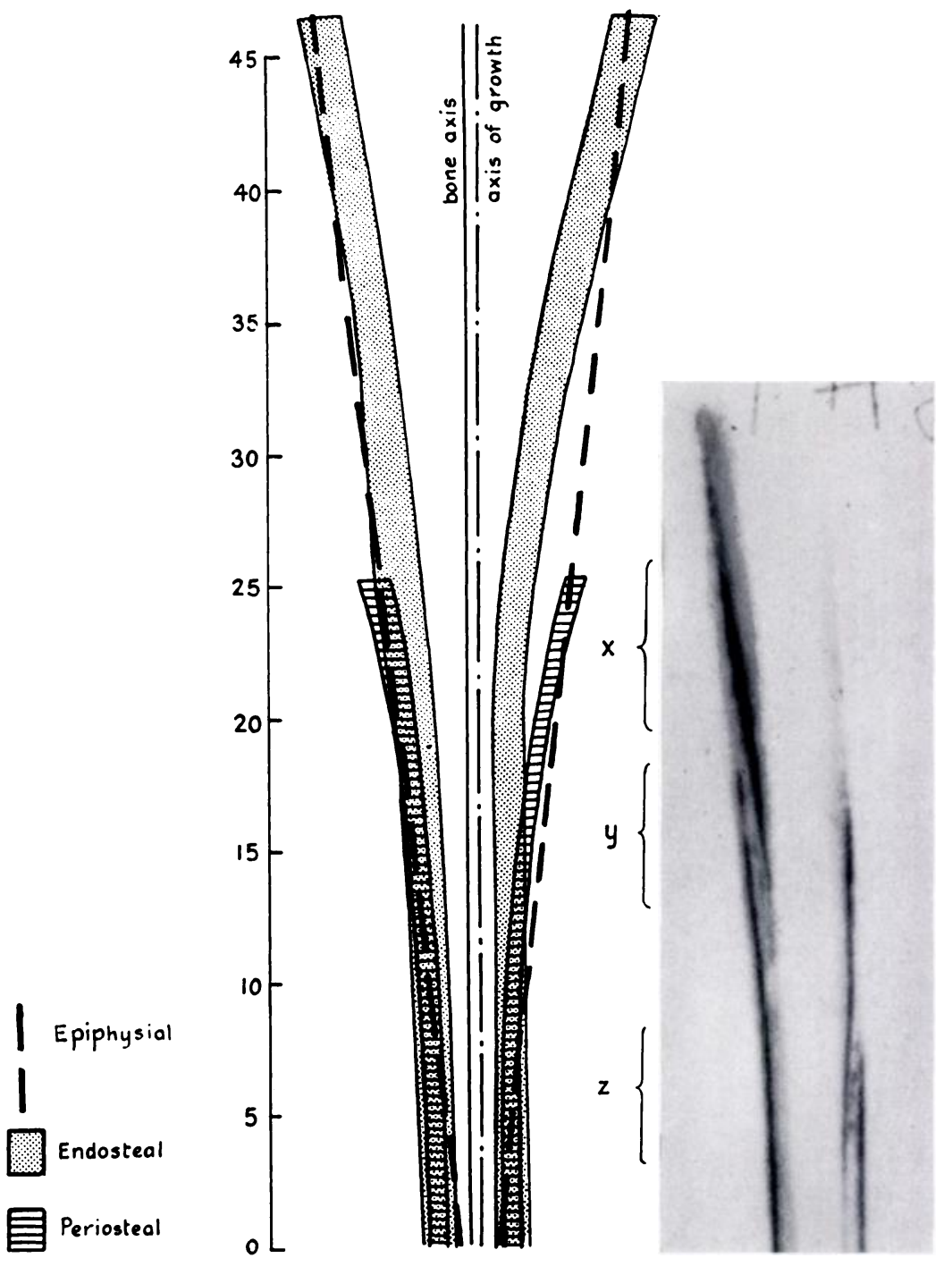

FIG. 29

FIG. 30

Figure 29-Diagrammatic representation of growth of proximal half of rabbit tibia during the period weanling to seven months. Longitudinal section. Figure 30-Autoradiograph prepared from longitudinal section showing retention of radioactive strontium in similar section of a rabbit tibia injected as weanling and killed six months later.

\section{SUMMARY}

1. The detailed anatomy and calcification of the upper half of the tibia in rabbits varying in age from six weeks to twelve months has been studied.

2 . The structure of the bone varies at different levels, but a section taken from the same level in the tibia from animals of the same age presents a reasonably constant picture.

3. It has been shown that this variation in structure at different levels is directly related to a 
difference between the axis of growth and the bone axis. This difference is a result of the unique shape of the tibia.

4. Autoradiographic studies confirm the localised concentration of radioactive strontium in areas of active bone formation where uptake is rapid.

5. The long retention of radioactive strontium in the skeleton (that is, the slow turnover) is a result of the slowness of resorption of bone (endosteal, periosteal or Haversian) in the cortex. Not only is the process slow but it is extremely localised.

6. The significance of these anatomical and physiological characteristics in relation to radiation injury is discussed.

This work was begun on behalf of the Protection Sub-Committee of the Medical Research Council's Committee on Medical and Biological Applications of Nuclear Physics.

\section{REFERENCES}

AMPRINo, R. (1952): Rapporti fra processi di ricostruzione e distribuzione dei minerali nelle ossa. I. Ricerche eseguite col metodo di studio dell' assorbimento dei raggi roentgen. Zeitschrift für Zellforschung, 37, 144. AMPrino, R., and Bairati, A. (1936): Processi di ricostruzione e di riassorbimento nella sostanza compatta delle ossa dell' uomo. Zeitschrift für Zellforschung, 24, 439.

Bisgard, J. D., and Bisgard, M. E. (1935): Longitudinal Growth of Long Bones. Archives of Surgery; 31, 568.

Brash, J. C. (1934): Some Problems in the Growth and Developmental Mlechanics of Bone. Edinburgh Medical Journal, 41, 305, 363.

Comar, C. L., Lotz, W. E., and Boyd, G. A. (1952): Autoradiographic Studies of Calcium, Phosphorus and Strontium Distribution in the Bones of the Growing Pig. American Journal of Anatomy, 90, 113.

Duhamel, H. L. (1742) (published 1745): Sur le Développement et la crûe des os des animaux. Histoire de l'Académie royale des Sciences: Mémoires de Mathématique et de Physique, p. 354.

Duhamel, H. L. (1743) (published 1746): Cinquième Mémoire sur les os. Dans lequel on se propose d'éclaircir par de nouvelles expériences comment se fait la crûe des os suivant leur longueur. Histoire de l'Académie royale des Sciences: Mémoires de Mathématique et de Physique, p. 111.

Gill, G. G., and ABbotr, L. C. (1942): Practical Method of Predicting the Growth of the Femur and Tibia in the Child. Archives of Surgery, 45, 286.

Hales, S. (1727): Statical Essays, Vol. 1, p. 339. London: W. Innys and T. Woodward.

HARRIS, H. A. (1933): Bone Growth in Health and Disease. London: Humphrey Milford Oxford University Press.

Hunter, J. (1772): See " Experiments and Observations on the Growth of Bones, from the Papers of the late Mr Hunter." In The Works of John Hunter, Vol. 4, p. 315, edited by James F. Palmer. London: Longman, Rees, Orme, Brown, Green, and Longman, 1835.

Jowsey, J., Rayner, B., Tutt, M., and Vaughan, J. (1953a): The Deposition of ${ }^{90} \mathrm{Sr}$ in Rabbit Bones following Intravenous Injection. British Journal of Experimental Pathology, 34, 384.

Jowsey, J., Owen, M., and Vaughan, J. (1953b): Microradiographs and Autoradiographs of Cortical Bone from Monkeys injected with ${ }^{90} \mathrm{Sr}$. British Journal of Experimental Pathology, 34, 661.

Jowsey, J., Owen, M., and Vaughan, J. (1955): Retention and Excretion of ${ }^{90} \mathrm{Sr}$ by Old Rabbits. British Journal of Experimental Pathology, 36, 22.

Kidman, B., Rayner, B., Tutt, M. L., and Vaughan, J. M. (1952): Autoradiographic Studies of the Deposition of $\mathrm{Sr}^{89}$ in Rabbit Bones. Journal of Pathology and Bacteriology, 64, 453.

LACrolx, P. (1951): The Organization of Bones. London: J. \& A. Churchill Ltd.

LAcroix, P. (1953): Sur le métabolisme du calcium dans l'os compact du chien adulte. Bulletin de l'Académie Royale de Médecine de Belgique, 18, 489.

Leblond, C. P., Wilkinson, G. W., Bélanger, L. F., and Robichon, J. (1950): Radio-Autographic Visualization of Bone Formation in the Rat. American Journal of Anatomy, 86, 289.

Neuman, W. F., and Weikel, J. H. (1954): The Recrystallization of Bone Nineral: an Evaluation of the Dynamics of Ca Metabolism. University of Rochester, U.R. 314.

PAyton, C. G. (1931-32): The Growth in Length of the Long Bones in the Madder-fed Pig. Journal of Anatomy, 66, 414.

Petersen, H. (1930): Die Organe des Skeletsystems. In W. von Möllendorff's Handbuch der mikroskopischen Anatomie des Menschen, II 2, p. 521. Berlin: Julius Springer.

Tomes, J., and DE Morgan, C.(1853): Observations on the Structure and Development of Bone. Philosophical Transactions of the Royal Society of London, 143, 109.

Tomlin, D. H., Henry, K. M., and Kon, S. K. (1953): Autoradiographic Study of Growth and Calcium Metabolism in the Long Bones of the Rat. British Journal of Nutrition, 7, 235. 